\title{
OPEN Comprehensive characterization of motor and coordination functions in three adolescent wild-type mouse strains
}

\begin{abstract}
Ahmed Eltokhi ${ }^{1,2,3 凶}$, Barbara Kurpiers ${ }^{2}$ \& Claudia Pitzer $^{2 \bowtie}$
Neuropsychiatric disorders are often associated with motor and coordination abnormalities that have important implications on the etiology, pathophysiology, and management of these disorders. Although the onset of many neuropsychiatric disorders including autism spectrum disorder, schizophrenia, and attention-deficit hyperactivity disorder emerges mainly during infancy and adolescence, most of the behavioral studies in mice modeling neuropsychiatric phenotypes are performed in adult animals, possibly missing valuable phenotypic information related to the effect of synaptic maturation during development. Here, we examined which behavioral tests assessing both motor and coordination functions can be performed in mice at two different adolescent stages. As strain and sex affect mouse behavior, our experiments covered both male and female mice of three inbred wild-type strains, C57BL/6N, DBA/2, and FVB/N. Adolescent mice of both postnatal days (P)2230 and P32-40 developmental stages were capable of mastering common motor and coordination tests. However, results differed significantly between strains and sexes. Moreover, the 10-day interval between the two tested cohorts uncovered a strong difference in the behavioral results, confirming the significant impact of maturation on behavioral patterns. Interestingly, the results of distinct behavioral experiments were directly correlated with the weight of mice, which may explain the lack of reproducibility of some behavioral results in genetically-modified mice. Our study paves the way for better reproducibility of behavioral tests by addressing the effect of the developmental stage, strain, sex, and weight of mice on achieving the face validity of neuropsychiatric disorder-associated motor dysfunctions.
\end{abstract}

For a long time, deficits in motor function in neuropsychiatric disorders have been traditionally neglected both in clinical practice and research despite their clinical and neurobiological relevance. Fortunately, they are now considered main diagnostic criteria of many neuropsychiatric disorders ${ }^{1}$. For instance, coordination and motor dysfunctions have been well documented in autism spectrum disorder (ASD $)^{2-6}$, schizophrenia ${ }^{7-11}$, attention-deficit hyperactivity disorder $(\mathrm{ADHD})^{12-14}$, and depression ${ }^{15-17}$ and have important implications for the etiology ${ }^{18,19}$, pathophysiology ${ }^{20}$, and management ${ }^{21,22}$ of these disorders. Moreover, they are considered established markers of illness episodes and severity ${ }^{19}$. These motor abnormalities vary greatly in different neuropsychiatric disorders. ASD patients are characterized by poor visual tracking, limited gross and fine motor functions when grasping or reaching for objects, inability to execute a sequence of actions (apraxia and difficulties in imitation), and postural balance difficulties ${ }^{23,24}$. Another class of motor-related alterations is observed in schizophrenia patients which include psychomotor slowing ${ }^{25,26}$, poor performance in complex motor tasks ${ }^{27,28}$, dystonia, akathisia, and hypokinesia ${ }^{27,29}$. On the other hand, $30 \%$ to $50 \%$ of children with ADHD show impaired gross motor and fine motor skills including difficulties in handwriting and clumsiness in performing motor skills, which can be attributed to their hyperactivity, impulsivity, and inattention ${ }^{13,30,31}$.

The onset of several neuropsychiatric disorders emerges mainly during infancy and adolescence ${ }^{32}$. Thus, $50 \%$ of adults with neuropsychiatric disorders received a diagnosis before 15 years of age ${ }^{33}$. Motor abnormalities in ASD and ADHD specifically appear within the first year of life $e^{30,34-38}$, and it is known that neuromotor

${ }^{1}$ Department of Neurology and Epileptology, Hertie Institute for Clinical Brain Research, University of Tübingen, Tübingen, Germany. ${ }^{2}$ Interdisciplinary Neurobehavioral Core, Heidelberg University, Heidelberg, Germany. ${ }^{3}$ Present address: Department of Pharmacology, University of Washington, Seattle, USA. ${ }^{\square}$ email: Eltokhi@uw.edu; Claudia.pitzer@pharma.uni-heidelberg.de 
a

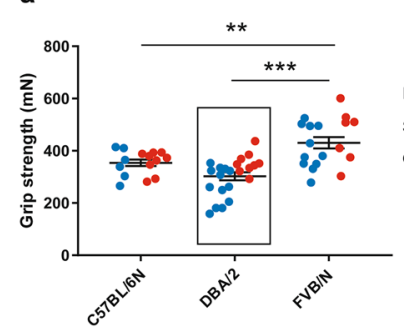

b

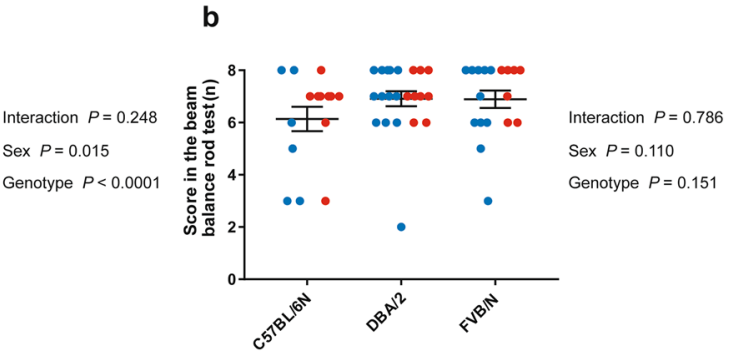

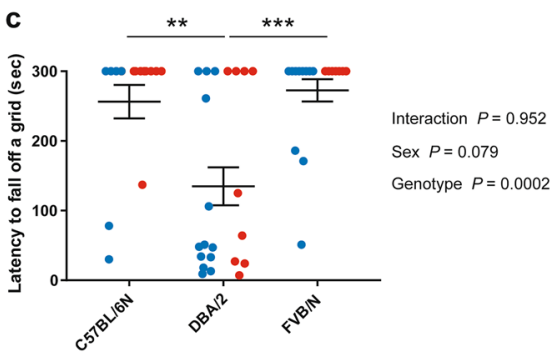

d

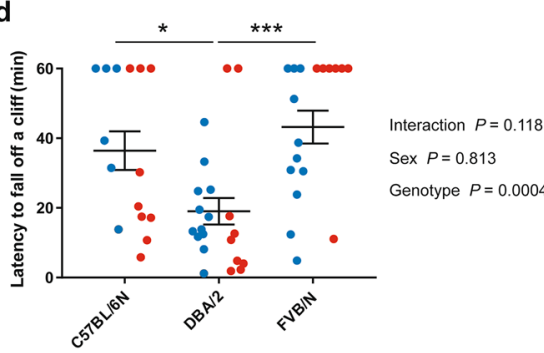

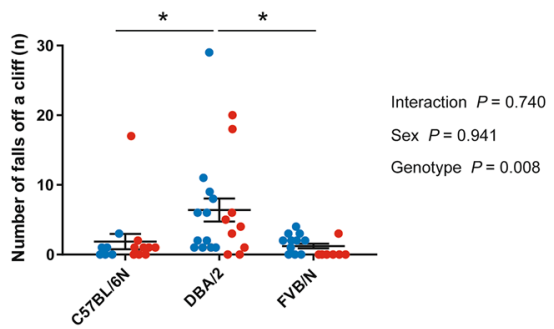

Figure 1. Coordination function in the P22-30 cohort of C57BL/6N, DBA/2, and FVB/N strains. (a) The grip strength test revealed increased grip strength for FVB/N mice compared to C57BL/6N and DBA/2 mice. (b) The beam balance rod test showed no difference between the three investigated strains. (c) DBA/2 mice displayed the lowest latency to fall off the grid in the inverted screen test. (d) In the cliff avoidance reaction test, DBA/2 mice exhibited the lowest latency to fall off the cliff (left) and the highest number of falls (right) compared to C57BL/6N and FVB/N mice. Two-way ANOVA followed by Tukey post hoc test, ${ }^{\star} p \leq 0.05$, ${ }^{* *} p \leq 0.01,{ }^{* * *} p \leq 0.001$. A black rectangle indicates a significant difference between sexes within a strain (see Supplementary Table 2). Blue and red dots refer to males and females, respectively. Error bars indicate the standard error of the mean (SEM).

dysfunction in schizophrenia is even present before the onset of the disease and constitute an important indicator of $\mathrm{it}^{39,40}$, with poor coordination, clumsiness, and unfamiliar movements being the most common motor abnormalities among children later on developing schizophrenia ${ }^{41}$. However, behavioral studies modeling neuropsychiatric disorders in genetically-engineered mouse lines are mostly performed in adulthood taking the advantages of easier handling and the capabilities of mastering more complex behavioral and cognitive tasks. Unfortunately, these studies miss valuable information on the impact of synaptic maturation during development. Yet, our previous studies unraveled the capacity of adolescent mice in performing experiments assessing neuropsychiatric-like phenotypes including communication deficits ${ }^{42}$, anxiety, social impairment, and cognitive dysfunction ${ }^{43}$.

In the present study, we aimed to investigate which behavioral tests recapitulating neuropsychiatric disorderassociated motor abnormalities can be performed in adolescent mice till P40. We have selected behavioral tests with high face validity that are commonly used to evaluate traits in sensory-motor functions. Our test battery included the grip strength, beam balance rod, inverted screen, cliff avoidance reaction, rotarod, and voluntary wheel running tests. As we have previously shown that behavioral results including ultrasonic vocalizations (USV) ${ }^{42}$ and home-cage activity ${ }^{43}$ are sensitive to a small developmental progress during adolescence, we performed our behavioral test battery on two cohorts of mice, one from P22 to P30 and the other from P32 to P40 in order to draw a full picture of the motor ability during adolescence. Because the genetic background and sexes are known to influence behavioral characteristics ${ }^{42-45}$, we performed our experiments on male and female mice of three different inbred strains, $\mathrm{C} 57 \mathrm{BL} / 6 \mathrm{~N}, \mathrm{DBA} / 2$, and $\mathrm{FVB} / \mathrm{N}$ that are world-wide used in research and are the standard strains in neuroscience with their ability to discern the role of individual genes and the impact of allelic variation along with decreased variability ${ }^{46-49}$.

Our work revealed that the motor activity and coordination functions during adolescence differ among these mouse strains, highlighting the potential advantages and disadvantages of individual strains in behavioral studies.

\section{Results}

Motor activity and coordination function in P22-30 cohort. The behavioral test battery started with measuring the grip strength of $\mathrm{P} 22$ mice. FVB/N mice revealed the most powerful grip strength compared to C57BL/6N $(P=0.007)$ and DBA/2 $(P<0.0001)$ mice (Fig. 1a). Notably, female DBA/2 mice showed a higher grip strength than males (Supplementary Table 2). For measuring coordination functions, we employed several tests. In the beam balance rod test at P23, no difference was found between the three investigated strains with a similar performance of male and female mice within each strain (Fig. 1b). In contrast, DBA/2 mice displayed the least coordination function in the inverted screen test by showing the lowest latency to fall off a grid compared to $\mathrm{C} 57 \mathrm{BL} / 6 \mathrm{~N}(P=0.002)$ and $\mathrm{FVB} / \mathrm{N}(P=0.0003)$ mice (Fig. 1c). In another test for measuring coordination and impulsivity, the cliff avoidance reaction test, DBA/2 mice revealed also the lowest latency to fall off a cliff $(P=0.026$ vs. C57BL/6N, $P=0.0008$ vs. $\mathrm{FVB} / \mathrm{N})$ and the highest number of falls $(P=0.046$ vs. C57BL/6N, 
a

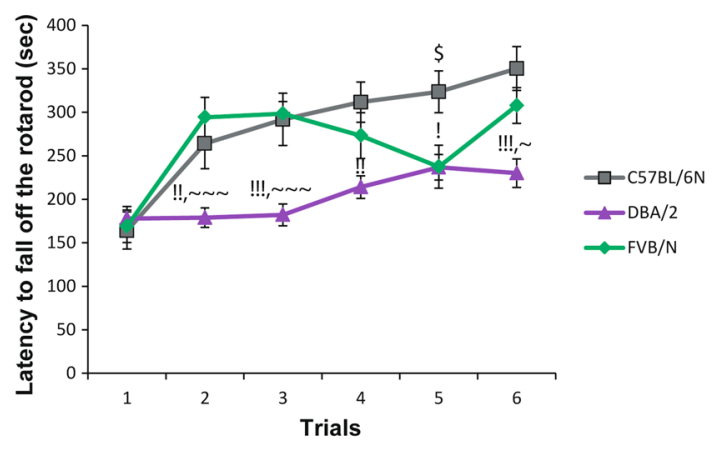

b

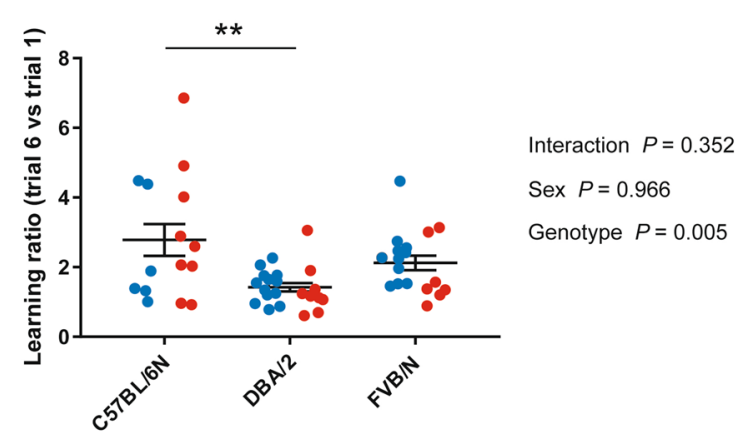

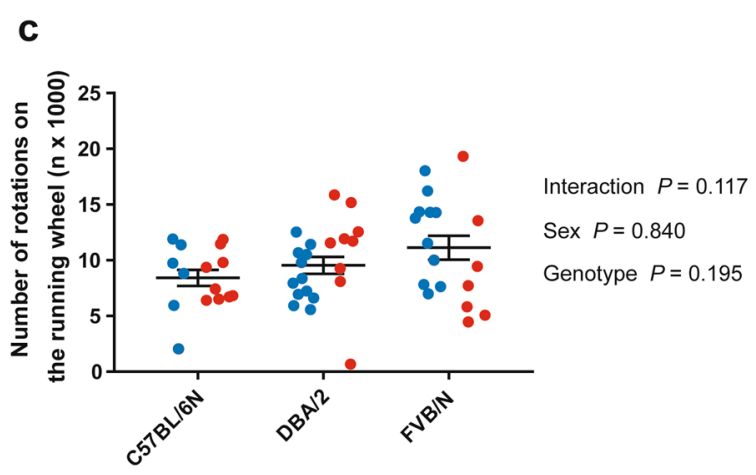

Figure 2. Motor activity in the P22-30 cohort of C57BL/6N, DBA/2, and FVB/N strains. (a) In the rotarod test, $\mathrm{DBA} / 2$ mice exhibited the lowest duration on the rotarod compared to $\mathrm{C} 57 \mathrm{BL} / 6 \mathrm{~N}$ and $\mathrm{FVB} / \mathrm{N}$ mice. For the detailed comparison between male and female mice within each strain, see Supplementary Fig. 2. (b) $\mathrm{C} 57 \mathrm{BL} / 6 \mathrm{~N}$ mice showed a significant better learning ability in the rotarod test compared to DBA/2 mice. (c) In the voluntary wheel running test, no difference between the three investigated strains was revealed. Twoway ANOVA followed by Tukey post hoc test, ! $p \leq 0.05$, !! $p \leq 0.01$ and !!! $p \leq 0.001$ for DBA/2 versus C57BL/6N; $\sim p \leq 0.05$ and $\sim \sim p \leq 0.001$ for $\mathrm{DBA} / 2$ versus $\mathrm{FVB} / \mathrm{N} ; \$ p \leq 0.001 \mathrm{C} 57 \mathrm{BL} / 6 \mathrm{~N}$ versus $\mathrm{FVB} / \mathrm{N} ;{ }^{* *} p \leq 0.01$. Blue and red dots refer to males and females, respectively. Error bars indicate the standard error of the mean (SEM).

$P=0.013$ vs. FVB/N) (Fig. 1d). No difference in the coordination function between male and female mice of the investigated strains was seen in either the inverted screen or cliff avoidance reaction tests (Supplementary Table 2).

For testing the motor activity of adolescent mice, we employed two tests, the rotarod and voluntary wheel running. In the rotarod test, $\mathrm{DBA} / 2$ mice displayed the lowest ability to perform the test by showing a decreased latency to fall off the accelerating rotarod, which reached significance compared to C57BL/6N in all trials except trial 1 that acted as a habituation trial (Trial 1: $P=0.846$ vs. $\mathrm{C} 57 \mathrm{BL} / 6 \mathrm{~N}, P=0.924$ vs. FVB/N; Trial 2: $P=0.007$ vs. $\mathrm{C} 57 \mathrm{BL} / 6 \mathrm{~N}, P=0.0001$ vs. FVB/N; Trial $3: P=0.0001$ vs. $\mathrm{C} 57 \mathrm{BL} / 6 \mathrm{~N}, P<0.0001$ vs. FVB/N; Trial $4: P=0.003$ vs. $\mathrm{C} 57 \mathrm{BL} / 6 \mathrm{~N}, P=0.073$ vs. FVB/N; Trial $5: P=0.012$ vs. $\mathrm{C} 57 \mathrm{BL} / 6 \mathrm{~N}, P=0.999$ vs. FVB/N; Trial $6: P=0.0005$ vs. C57BL/6N, $P=0.02$ vs. FVB/N) (Fig. 2a). Interestingly, female C57BL/6N mice showed a better motor function in the rotarod test compared to males in trials 2, 3, and 4 (Supplementary Fig. 2; Supplementary Table 2). To check the ability of mice to learn the test, the performance of each mouse in trial 6 was compared to trial 1. C57BL/6N mice revealed the highest motor learning ability and reached significance compared to DBA/2 mice $(P=0.002$ vs. DBA/2, $P=0.219$ vs. FVB/N) (Fig. $2 \mathrm{~b})$. On the other hand, the activity of the three investigated strains in the voluntary wheel running test was comparable with no difference between male and female mice within each strain (Fig. 2c; Supplementary Table 2).

Motor activity and coordination function in P32-40 cohort. The grip strength test at P32 revealed that $\mathrm{FVB} / \mathrm{N}$ mice displayed the most powerful grip strength $(P<0.0001$ vs. C57BL/6N and DBA/2) with DBA/2 mice showing the least grip strength $(P=0.0003$ vs. $\mathrm{C} 57 \mathrm{BL} / 6 \mathrm{~N})$ and $\mathrm{C} 57 \mathrm{BL} / 6 \mathrm{~N}$ mice being intermediate (Fig. 3a). Compared to the grip strength test performed at P22, the three investigated strains at $\mathrm{P} 32$ showed no difference between male and female mice (Supplementary Table 2). In the beam balance rod test, FVB/ $\mathrm{N}$ mice showed a lower score compared to C57BL/6N $(P=0.023)$ and DBA/2 $(P=0.021)$ mice (Fig. 3b). In the inverted screen test, DBA/2 mice showed the lowest latency to fall off the grid but reached significance only compared to $\mathrm{FVB} / \mathrm{N}(P=0.041)$ (Fig. 3c). In both beam balance rod and inverted screen tests, no difference between male and female mice within strain was found (Supplementary Table 2). In the cliff avoidance reaction test, the three investigated strains exhibited comparable coordination function with no difference in the latency or number of falls off the cliff (Fig. 3d). In contrast to the cliff avoidance reaction test performed at P28 which showed no dif- 
a

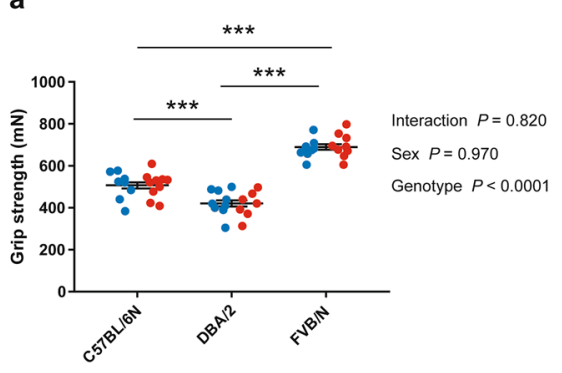

b

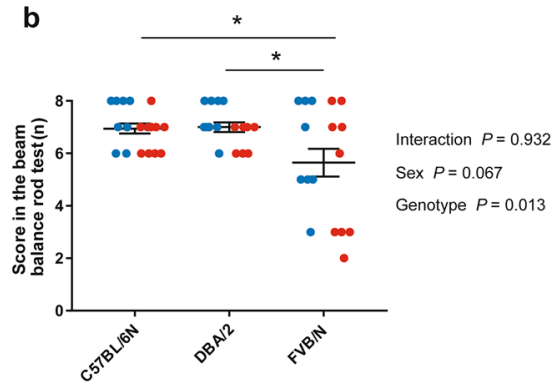

C

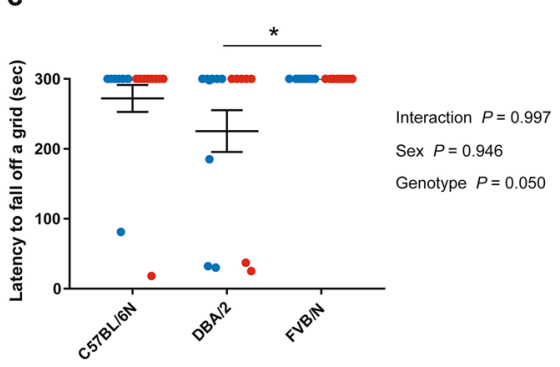

d
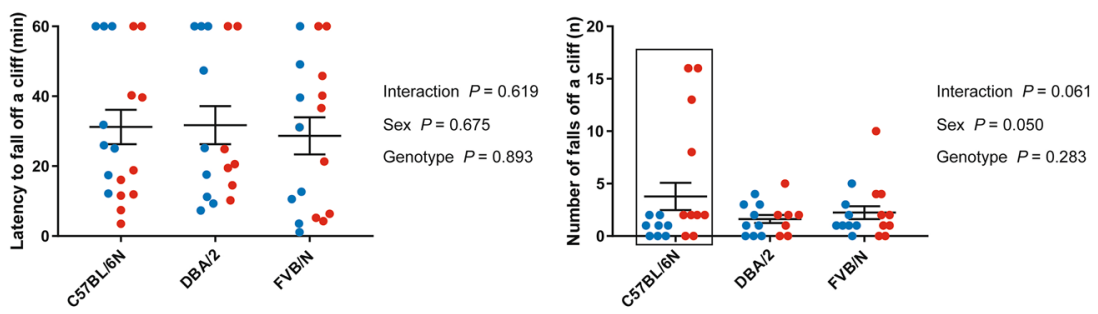

Figure 3. Coordination function in the P32-40 cohort of C57BL/6N, DBA/2, and FVB/N strains. (a) The grip strength test revealed $\mathrm{FVB} / \mathrm{N}$ displaying the most powerful grip strength, $\mathrm{DBA} / 2$ showing the least grip strength with $\mathrm{C} 57 \mathrm{BL} / 6 \mathrm{~N}$ being intermediate. (b) $\mathrm{FVB} / \mathrm{N}$ displayed the lowest score in the beam balance rod test compared to C57BL/6N and DBA/2. (c) DBA/2 mice had the lowest latency to fall off a grid in the inverted screen test and reached significance compared to FVB/N mice. (d) In the cliff avoidance reaction test, no difference in the latency to fall off a cliff (left) or the number of falls (right) between the three investigated strains. Two-way ANOVA followed by Tukey post hoc test, ${ }^{*} p \leq 0.05,{ }^{* * *} p \leq 0.001$. A black rectangle indicates a significant difference between sexes within a strain (see Supplementary Table 2). Blue and red dots refer to males and females, respectively. Error bars indicate the standard error of the mean (SEM).

ference between male and female mice, P38 C57BL/6N female mice showed a higher number of falls compared to males (Supplementary Table 2).

Similar to the rotarod test performed at P26-27, P36-37 DBA/2 mice displayed the worst motor activity by showing a decreased latency to fall off the rotarod, which reached significance compared to $\mathrm{FVB} / \mathrm{N}$ in all trials except trial 1 (Trial 1: $P=0.591$ vs. C57BL/6N, $P=0.28$ vs. FVB/N; Trial 2: $P=0.121$ vs. C57BL/6N, $P=0.028$ vs. FVB/N; Trial 3: $P=0.012$ vs. $\mathrm{C} 57 \mathrm{BL} / 6 \mathrm{~N}, P=0.014$ vs. FVB/N; Trial $4: P=0.027$ vs. $\mathrm{C} 57 \mathrm{BL} / 6 \mathrm{~N}, P=0.001$ vs. FVB/N; Trial 5: $P<0.0001$ vs. C57BL/6N, $P<0.0001$ vs. FVB/N; Trial $6: P<0.0001$ vs. C57BL/6N, $P=0.005$ vs. FVB/N) (Fig. 4a). Interestingly, female C57BL/6N mice showed better motor function in the rotarod test compared to males with borderline significance in trial 2 and significant difference in trial 3 (Supplementary Fig. 3; Supplementary Table 2). For motor learning, C57BL/6N mice showed the highest ability to learn the test and reached significance compared to DBA/2 mice $(P=0.041$ vs. DBA $/ 2, P=0.149$ vs. FVB/N) (Fig. $4 \mathrm{~b})$. Similar to the rotarod test, DBA/2 mice displayed the lowest number of rotations in the voluntary wheel running test compared to $\mathrm{C} 57 \mathrm{Bl} / 6 \mathrm{~N}$ and $\mathrm{FVB} / \mathrm{N}(P<0.0001)$ mice (Fig. 4c). Additionally, FVB/N female mice showed an increase in the number of rotations compared to males (Supplementary Table 2).

Comparison between the two developmental stages within each strain. To test whether the age difference of 10 days can affect the motor and coordination functions during adolescence, results of the behavioral test battery were compared between the two cohorts. In the grip strength test, all of the three investigated strains displayed increased grip strength with age (Fig. 5a). In contrast, other tests revealed inconsistent results between strains with FVB/N exhibiting a lower score in the beam balance rod test (Fig. 5b) and DBA/2 showing increased latency to fall off a grid in the inverted screen test in older mice (Fig. $5 \mathrm{c}$ ). In the cliff avoidance reaction test, the latency to fall off a cliff in FVB/N mice, and the number of falls in DBA/2 mice were decreased with age (Fig. 5d). Interestingly, in the voluntary wheel running test, the number of rotations of C57BL/6N and FVB/N mice was increased with age in contrast to the number of rotations of DBA/ 2 mice which was decreased in older mice (Fig. 5e).

Correlation between the weight of mice and performance in the motor and coordination tests. To test whether the weight of mice can be a factor in determining the performance on various motor and coordination tests, we calculated the Pearson's correlation coefficient for each test in the behavioral test battery for the P32-40 cohort. Only the grip strength and inverted screen tests were positively correlated with the weight of mice (Grip strength: Pearson's $r=0.7068, p<0.0001$; Inverted screen: Pearson's $r=0.4543, p=0.0008$; Beam balance rod test: Pearson's $r=-0.1476, p=0.303306$; Latency to fall in the cliff avoidance: Pearson's $r=0.0394, p=0.783698$; Number of falls in the cliff avoidance: Pearson's $r=-0.2059, p=0.148999$; Voluntary 
a

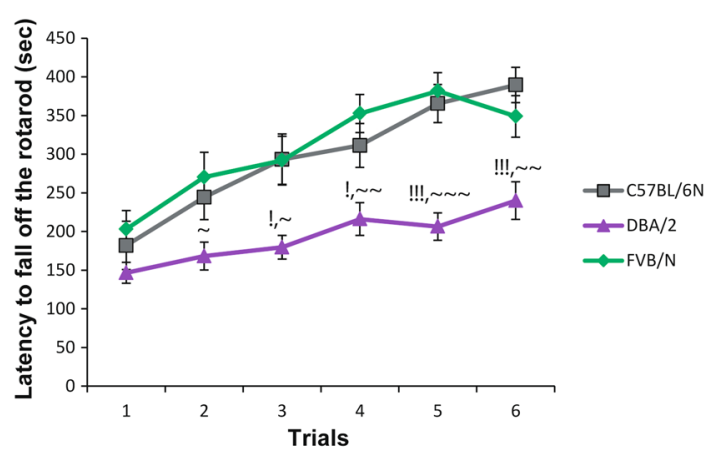

b

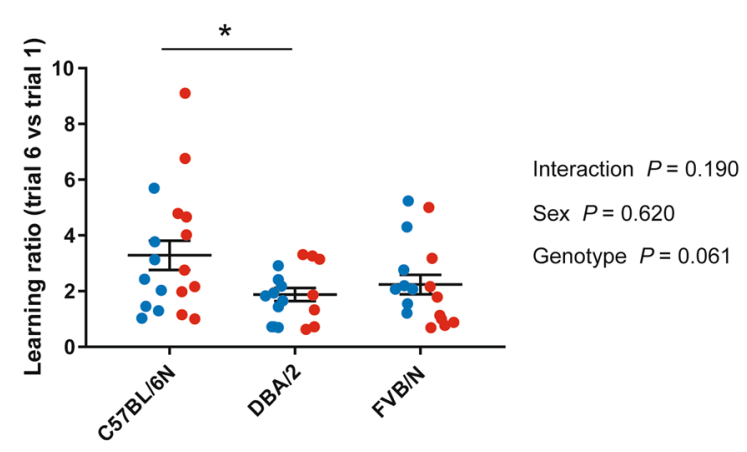

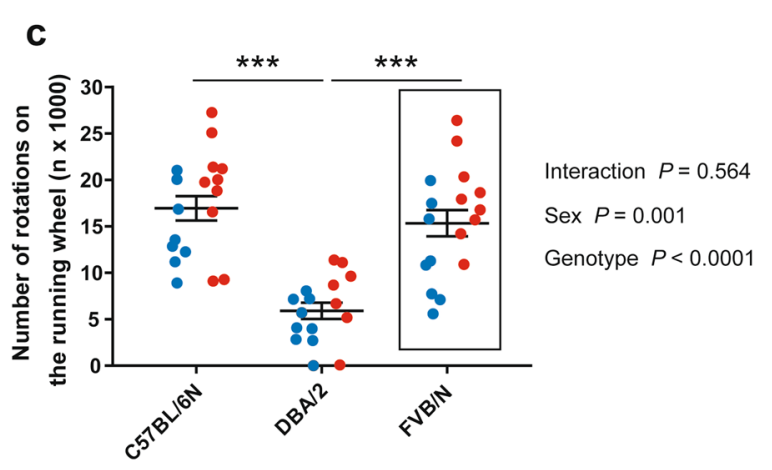

Figure 4. Motor activity in the P32-40 cohort of C57BL/6N, DBA/2, and FVB/N strains. (a) In the rotarod test, $\mathrm{DBA} / 2$ mice exhibited the lowest duration on the rotarod compared to C57BL/6N and FVB/N mice. For the detailed comparison between male and female mice within each strain, see Supplementary Fig. 3. (b) $\mathrm{C} 57 \mathrm{BL} / 6 \mathrm{~N}$ mice showed a significant better learning ability in the rotarod test compared to DBA/2 mice. C) In the voluntary wheel running test, $\mathrm{DBA} / 2$ mice displayed the lowest number of rotations. Two-way ANOVA followed by Tukey post hoc test, ! $p \leq 0.05$ and !!! $p \leq 0.001$ for DBA/2 versus C57BL/6N; $p \leq 0.05, \sim \sim p \leq 0.01$ and $\sim \sim p \leq 0.001$ for $\mathrm{DBA} / 2$ versus $\mathrm{FVB} / \mathrm{N} ;{ }^{*} p \leq 0.05,{ }^{* * *} p \leq 0.001$. A black rectangle indicates a significant difference between sexes within a strain (see Supplementary Table 2). Blue and red dots refer to males and females, respectively. Error bars indicate the standard error of the mean (SEM).

wheel running: Pearson's $r=0.1292, p=0.366211$ ). These results indicate that the increased body weight of mice can increase the grip strength and thus, the latency to fall off a grid.

\section{Discussion}

Studying the behavior of genetically-modified rodents modeling neuropsychiatric disorders contributes to our understanding of the pathophysiology of these disorders and enhances the development of new therapeutics. Therefore, it is important to perform behavioral experiments during the developmental time window that matches the onset of symptoms in humans before or around puberty corresponding to $\mathrm{P} 42$ in mice ${ }^{50,51}$. In our previous studies, we showed that several experiments assessing different behavioral domains related to neuropsychiatric disorders can be performed during adolescence ${ }^{42,43}$. These tests included USV recording, LABORAS, anxietyrelated tests (Open field, elevated plus maze, dark/light compartment, and hole-board tests), and cognitive tests (Puzzle box, fear conditioning, and active place avoidance tests). As motor abnormalities in neuropsychiatric disorders appear even before the onset of the core symptoms, it becomes mandatory to assess motor functions in young mice. Moreover, impaired motor functions can influence findings in other tasks, such as cognitive tests.

We here investigated which behavioral experiments assessing motor activity and coordination function can be performed during adolescence and established baseline levels of motor ability for three inbred wild-type mouse strains commonly used in biomedical and behavioral research. Our test battery covered the most frequently used assays including the grip strength, beam balance rod, inverted screen, cliff avoidance reaction, rotarod, and voluntary wheel running tests. To our knowledge, this is the first comprehensive study performed in young mice thoroughly exploring motor functions in different inbred strains. All three strains showed the ability to perform these tests in two developmental stages of adolescence. However, the three strains differed, with DBA/2 mice displaying weaker motor and coordination functions. These strain variations stress that the results of motor functions should be included to correctly interpret the outcome of other behavioral tests.

The rotarod test is one of the oldest tests that has been extensively used to assess the innate motor ability in mice since $1950 \mathrm{~s}^{52,53}$. Moreover, by performing several trials over multiple days, the rotarod test can unravel the motor learning ability that can indicate the degree of synaptic plasticity in various mouse strains during different developmental stages. Three studies comprehensively compared the performance of several inbred mouse strains on the rotarod. In the first study by Tarantino et al. (2000), four mouse strains, C57BL/6J, C3HeB/FeJ, DBA/2J, 


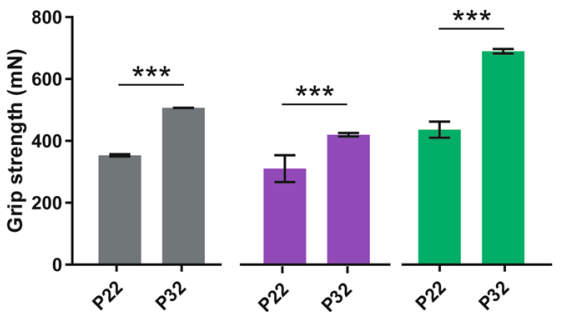

d

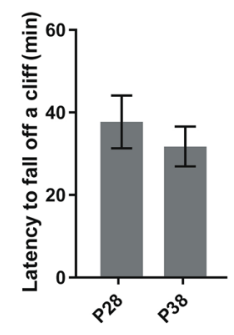

b
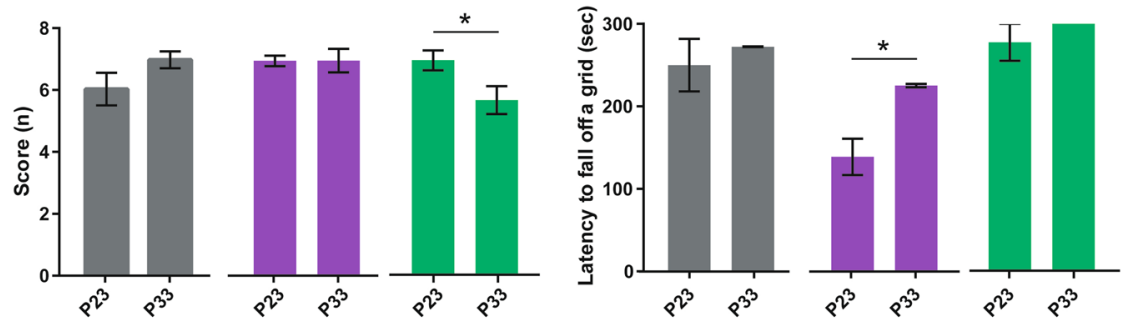

e

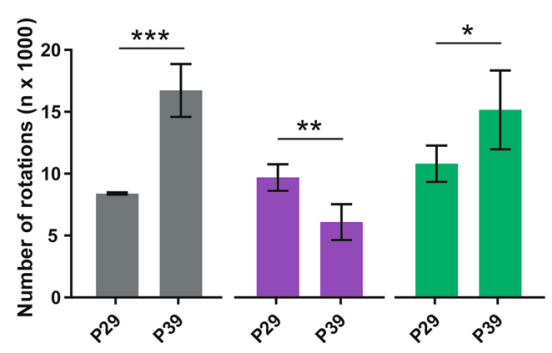

Figure 5. Comparison between the $\mathrm{P} 22-30$ and $\mathrm{P} 32-40$ cohorts within $\mathrm{C} 57 \mathrm{BL} / 6 \mathrm{~N}, \mathrm{DBA} / 2$, and FVB/N strains. (a) The grip strength was increased with age in the three investigated strains. (b) In the beam balance rod test, only FVB/N mice showed a decreased score in older mice. (c) The latency to fall off a grid in the inverted screen test was increased in older DBA/2 mice. (d) In the cliff avoidance reaction test, FVB/N mice exhibited lower latency to fall off a cliff (left) and DBA/2 showed a decreased number of falls (right). e) The voluntary wheel running test revealed inconsistent results in different strains with $\mathrm{C} 57 \mathrm{BL} / 6 \mathrm{~N}$ and $\mathrm{FVB} / \mathrm{N}$ mice showing an increase in the number of rotations with age in contrast to DBA/2 mice. Two-way ANOVA followed by Tukey post hoc test, ${ }^{*} p \leq 0.05,{ }^{* *} p \leq 0.01,{ }^{* *} p \leq 0.001$. Error bars indicate the standard error of the mean (SEM).

and 129/SvImJ, and aged around P60 were compared in an accelerating rotarod paradigm with three trials per day for two consecutive days ${ }^{54}$. Consistent with our finding, C57BL/6J mice stayed longer on the rotarod than DBA/2J mice. In the second study, the ability of eight inbred strains to perform on the rotarod was investigated with nine trials across three days ${ }^{55}$. In that study, C57BL/6J mice exhibited better performance on the rotarod compared to DBA/2J and FVB/NJ mice consistent with our findings ${ }^{55}$. When comparing the two previously mentioned studies together, DBA/2J mice performed better and showed increased motor learning in Tarantino et al. ${ }^{54}$ study than in McFadyen et $a .^{55}$, which can be explained by the different protocols used in both studies. In the third study in young mice aged 5-6 weeks, again consistent with our results, C57BL/6J mice had the highest latencies for remaining on the rotarod compared to DBA/2J and $\mathrm{FVB} / \mathrm{NJ}^{56}$. However, these results were in contrast to a previous study by the same group showing no difference between C57BL/6J, DBA/2J, and FVB/ $\mathrm{NJ}$ mice ${ }^{57}$. On the other hand, motor and coordination functions differed between substrains. C57BL/6J mice exhibited significantly longer latencies than $\mathrm{C} 57 \mathrm{BL} / 6 \mathrm{~N}$ and $\mathrm{C} 57 \mathrm{BL} / 6 \mathrm{C}$ mice $^{58}$. Thus, care needs to be taken when comparing the results of studies in different mouse substrains. Notably, in our study, several mice made passive rotations i.e., mice held onto the bar and rotated for at least one revolution. If a mouse clings onto the rod in the rotarod test instead of running on top of it, no conclusions about its balance and coordination can be made ${ }^{59,60}$. Accordingly, we considered the first passive rotation of a mouse as the end of the trial since it can indicate the lost capability in the rotarod performance. As some laboratories consider the fall of the mouse off the rotarod as an endpoint, the different evaluation protocols will, at least partly, account for the lack of inter-laboratory reproducibility. Additionally, the apparatus itself including the diameter of the rod, material covering the rod, speed, and rate of acceleration of the rod can also impact the variability of behavioral results between laboratories ${ }^{59,61,62}$.

Surprisingly, different coordination tests revealed intrastrain diverging results. For example, the P22-30 DBA/2 mice showed less coordination in the inverted screen and cliff avoidance tests but not the beam balance rod test. This implies that several behavioral tests assessing motor activity and coordination function need to be approached for a full characterization of genetically-engineered mice modeling neuropsychiatric disorders.

Measuring motor function in both male and female mice is of particular relevance as the susceptibility to neuropsychiatric disorders differs between males and females with a ratio of $4: 1$ in ASD $^{63-66}, 1.4: 1$ in schizophrenia ${ }^{67,68}, 4: 1$ in attention-deficit hyperactivity disorder ${ }^{69-72}$ and $1: 2$ in depression ${ }^{73-78}$. Additionally, neuropsychiatric disorders exhibit sex differences in the age of onset, disease progression, and disease severity ${ }^{79,80}$. Females are known to reach puberty, the major feature of adolescence ${ }^{81}$, before males, which can have an impact on the behavior during this sensitive period. Various markers are used to determine puberty in mice including the vaginal opening, first vaginal cornification, onset of cyclicity in females and balanopreputial separation in males. These different markers make it difficult to determine the precise date of puberty in mice. Additionally, differences in the onset of puberty have been reported in different inbred strains, which add another layer of complexity in comparing the behavioral results of different strains. For instance, the vaginal opening in female 
DBA/2J and C57BL/6J mice occur, on average, at P25.78 and P26.45, respectively ${ }^{82}$. In contrast, the onset of cyclicity was earlier in female C57BL/6J (P48.67) than DBA/2J (P51.11) mice. For males, the occurrence of the balanopreputial separation was earlier in C57BL/6J (P29.71) than DBA/2J (P34) mice ${ }^{82}$. To this end, a rough dating of puberty in conventional preclinical models using laboratory wild-type and genetically modified mice is recommended for the accurate characterization of the behavioral outcome.

In our study, the C57BL/6N strain showed in the rotarod test the strongest difference between male and female mice with better performance by the latter. The difference being stronger in P26-27 than P36-37 mice may indicate an interrelation between age and sex. The better performance of female than male C57BL/6N mice is consistent with two previous findings in C57BL/6J mice tested at different ages ${ }^{55,83}$. In P60-90 mice, female C57BL/6J mice had longer latency to fall off the rotarod than males ${ }^{55}$. In another study, female P30 C57BL/6J mice showed a trend towards increased duration on the rotarod, which reached significance at $\mathrm{P} 150^{83}$, again confirming the effect of age on distinct behaviors. In contrast to C57BL/6N, DBA/2 mice in our study revealed no difference between males and females in both cohorts in all tests except the grip strength at P22. These results are consistent with a study showing no sex difference in DBA/2 mice in the rotarod test ${ }^{55}$ and with our previous study revealing no sex differences in DBA/2 mice in other behavioral tests related to neuropsychiatric disorders ${ }^{43}$. Furthermore, female FVB/N mice revealed more activity than males on the running wheel at P39, which is in line with our previous results showing a higher activity of P36 females in the home cage LABORAS test ${ }^{43}$. In summary, the sex-specific differences in motor activity and coordination function stress the necessity of testing both males and females in phenotyping mouse models of neuropsychiatric disorders.

The 10-day interval between the two tested cohorts displayed strong differences in the behavioral outcome, mainly depending on the investigated strain and behavioral paradigm. Indeed, several studies revealed aging from young to middle age inducing not only increased body weight ${ }^{84}$ but also reduced rotarod performance ${ }^{85,86}$, and altered locomotor activity ${ }^{87}$. Our results highlight the importance of small developmental windows and stress the importance of comparing mice of the same age since a few days' differences can have a strong impact on the behavioral pattern.

The positive correlation between the weight of the mouse and performance on the grip strength and inverted screen tests needs to be taken into consideration when characterizing motor functions. Taking the weight into account can enhance the reproducibility of behavioral tests in genetically-modified mouse models, a main issue in the behavioral neuroscience field ${ }^{88}$. Consistent with a previous study performed on P30 and P150 C57BL/6J mice $^{83}$, our analysis of male and female C57BL/6N mice revealed no statistically significant correlation between the body weight and rotarod performance. In contrast, a significant negative correlation was found in P60-90 $\mathrm{C} 57 \mathrm{BL} / 6 \mathrm{~J} \mathrm{mice}{ }^{55}$. The discrepancy of the results in the aforementioned studies likely relies on age differences.

As young mice are more active and hectic than adult mice, the animal-experimenter interaction can have an impact on the behavioral results. Because high standardization facilitates inter-laboratory reproducibility, increases efficiency, and reduces variability ${ }^{89}$, many automated methods with minimum handling of mice such as automated home-cage wheel-running ${ }^{90}$, CatWalk gait analysis ${ }^{91}$, and Erasmus ladder test ${ }^{92}$, are meanwhile replacing manual ones. These tests with a little interaction with mice will allow more precise characterization of motor function, coordination, and motor learning. However, careful attention to other confounding variables during testing, statistical analysis and interpretation remain important and require consideration. In addition to the experimenter and way of handling ${ }^{93,94}$, a large array of factors can impact the behavioral outcome of rodents. Some published examples are the cage type, density and its type of enrichment ${ }^{93,95-97}$, and even the cage position on the rack in the vivarium ${ }^{98}$ can significantly alter rodent behavior. Geographical location also can affected body weight, motor coordination, and motor learning capability of wild-type mice, which partially relied on the rodent diet and water quality ${ }^{83}$. Therefore, all these factors must be ruled out for approaching genuine differences in motor function and learning.

In brief, differences in motor function as determined by performance in different motor and coordination tests uncovered the genetic difference as an important determinant in motor performance. Moreover, our study paves the way for better reproducibility of behavioral tests by addressing the effect of age during adolescence, sex, and weight on achieving the face validity of neuropsychiatric disorder-associated motor dysfunctions. Accordingly, behavioral characterization of knockout/knockin mice are recommended having littermates of the same delivery day, alike male/female ratios, and weight should be checked before and after every motor test since these three factors can strongly shift the results. Keeping these factors in mind will decrease variability, increase the face validity of the rodent model and concomitantly allow better defining "disease progression" and drug efficacy in motor abnormalities.

\section{Materials and methods}

Animals and housing conditions. Animals and housing conditions were similar to our previous study ${ }^{43}$. All procedures were conducted in strict compliance with national and international guidelines for the Care and Use of Laboratory Animals. The experiments on mice were approved by the local government (Regierungspräsidium Karlsruhe, Germany G-102/16) and were carried out in compliance with the ARRIVE guidelines.

Experimental design and groups. All behavioral tests were carried out during the daylight cycle. Mice were brought into the behavioral room half an hour before the behavioral testing. Behavioral tests started at 7 am. We analyzed the behavior in 2 cohorts of group-housed mice of both sexes with one cohort starting at P22 till P30 and the second starting at P32 till P40. The number of mice per cohort and the type of the behavioral experiments are listed (Table 1). One male DBA/2 mouse died during the testing procedure and was not tested in the cliff avoidance reaction or voluntary wheel running tests in the P22-P30 cohort. 


\begin{tabular}{|c|c|c|c|c|c|}
\hline \multirow[b]{2}{*}{ Cohorts } & \multirow[b]{2}{*}{ Strains } & \multicolumn{2}{|l|}{ Mice (\#) } & \multirow[b]{2}{*}{ Number of litters } & \multirow[b]{2}{*}{ Behavioral test at postnatal day $(\mathbf{P} \#)$} \\
\hline & & Male $\hat{\alpha}$ & Female ${ }_{+}$ & & \\
\hline \multirow{5}{*}{$\mathrm{P} 22-30$} & & & & & Grip strength (P22) \\
\hline & C57BL/6N & 6 & 9 & 2 & Beam balance rod test/Inverted screen test (P23) \\
\hline & $\mathrm{DBA} / 2$ & 13 & 9 & 3 & Rotarod (P26-27) \\
\hline & FVB/N & 11 & 7 & 3 & Cliff avoidance reaction test (P28) \\
\hline & & & & & Voluntary wheel running activity (P29-30) \\
\hline \multirow{5}{*}{ P32-40 } & & & & & Grip strength (P32) \\
\hline & C57BL/6N & 8 & 10 & 2 & Beam balance rod test/Inverted screen test (P33) \\
\hline & $\mathrm{DBA} / 2$ & 9 & 7 & 3 & Rotarod (P36-37) \\
\hline & FVB/N & 8 & 9 & 2 & Cliff avoidance reaction test (P38) \\
\hline & & & & & Voluntary wheel running activity (P39-40) \\
\hline
\end{tabular}

Table 1. Mouse cohorts, number and age of the adolescent mice used in the different experiments.

The grip strength test was the first test to be applied to each cohort. One day later, we applied the beam balance rod test in the morning and the inverted screen test in the afternoon. Animals were maintained in the test room during this period. Then, we left the mice for two days without any experiments. At P26 and P36, we performed the rotarod test as one training trial permitting the mice to be habituated to the apparatus and to learn the task and two additional trials on the same day. On the following day, the data of three additional trials were collected. At P28 and P38, the cliff avoidance reaction test was performed. At P29 and P39, the voluntary wheel running test was performed for $24 \mathrm{~h}$. The weights of male and female mice were measured before performing the tests and are shown in Supplementary Fig. 1 and Supplementary Table 1.

After each trial, the apparatuses were carefully cleaned with $75 \%$ ethanol solution wetted tissue paper. All behavioral experiments were performed in a randomized manner with a separation of experiment conduction and data analysis.

The behavioral test battery. The grip strength test. The strength of the forelimb, as well as the overall neuromuscular strength, were tested using a grip strength meter (Ugo Basile, Gemonio, Italy, model 47106), which automatically measured the force $(\mathrm{mN})$ needed for the mouse to release a grip after having to grasp and cling to it. During this task, the mouse was held by the tail. After an initial training session, the mice were tested for one session. A test session is consisting of three consecutive trials and the final result was calculated as the average of these three trials.

The beam balance rod test. The time during which the mouse was able to remain on a narrow, elevated rod without falling was measured. The apparatus is composed of 7 rods with diameters of $6,8,12,15,20,25$, and $32 \mathrm{~mm}$, respectively. The length of each rod was $50 \mathrm{~cm}$ with a height of $20 \mathrm{~cm}$ above the ground. The mouse was put on each rod for $10 \mathrm{~s}$ starting from the widest to the narrowest. The score was calculated by the number of rods from which the tested mouse did not fall. If the mouse did not fall, the score was considered 8 . The test was performed twice with $1 \mathrm{~h}$ interval.

The inverted screen test. Muscle strength using all four limbs was tested in a modified version of the inverted screen test. The mouse was placed in the center of a metal grid screen. The grip screen is then carefully rotated to an inverted position and held steadily $45 \mathrm{~cm}$ above an empty cage containing bedding. The latency to fall off the grid was recorded with a maximum trial time of $5 \mathrm{~min}$.

The rotarod test. The accelerated rotarod (Ugo Basile, Gemonio, Italy, model 47600) test is a standard sensorymotor test to investigate animals' motor coordination and learning skills by measuring the ability of the mouse to stay and run on the accelerated rod. The test was performed for a duration of $8 \mathrm{~min}$ with an acceleration of 4-40 rpm. As soon as a mouse fell off the rod or started to rotate with the rotarod without running, the time was stopped. After an initial training trial, mice were tested for five trials over two days. The recovery phase between trials was $10 \mathrm{~min}$.

The cliff avoidance reaction test. The cliff avoidance reaction assesses coordination and maladaptive impulsive behavior. It was assessed using a round plastic platform (diameter, $20 \mathrm{~cm}$ ) supported by a rod (height $50 \mathrm{~cm}$ ) similar to a bar stool ${ }^{99}$. The floor below the platform was carpeted with smooth tissue to prevent injury if the animal fell. The test was initiated by gently placing the animal on the middle of the platform. The latency from an initial placement on the platform until falling was recorded. Mice that fell off the platform were immediately put back on the platform and the total number of falls during the entire session (60 min) was counted.

The voluntary wheel running test. The voluntary wheel running test was modified from ${ }^{100}$. Mice were placed individually in cages containing a running wheel and free access to food and water. The unrestricted voluntary 
wheel running activity started at 7-8 am and was digitally recorded for $24 \mathrm{~h}$ using the AWM counter (Lafayette Instrument, Louisiana, USA) that uses an optical sensor to detect the total revolutions of the wheel and is connected to a USB Interface and PC running an AWM Software (Lafayette Instrument, Louisiana, USA).

Statistical analysis. Two-way ANOVA was used with sex and genotype as the two factors. This was followed by Tukey's post hoc test for multiple comparisons to determine differences between the three strains $\mathrm{C} 57 \mathrm{BL} / 6 \mathrm{~N}, \mathrm{DBA} / 2$, and FVB/N and Bonferroni correction to check differences between males and females within each strain. To compare the two developmental stages (P22-30) and (P32-40) within each strain, twoway ANOVA was used with sex and age as the two factors. Additionally, a correlation analysis between the weight of P32-40 mice and their performance on the tests was done and is discussed in the results section. All data were expressed as mean \pm SEM. A $P$ value $\leq 0.05$ was considered statistically significant. Statistical analysis was performed using GraphPad Prism 7 and Microsoft Office Excel software. The respective numbers of male and female mice are described in Table 1 and the individual figures.

Received: 18 January 2021; Accepted: 2 March 2021

Published online: 22 March 2021

\section{References}

1. American Psychiatric Association. Diagnostic and Statistical Manual of Mental Disorders : DSM-5 (American Psychiatric Association, Washinton, D.C., 2013).

2. Ming, X., Brimacombe, M. \& Wagner, G. C. Prevalence of motor impairment in autism spectrum disorders. Brain Dev. 29, 565-570. https://doi.org/10.1016/j.braindev.2007.03.002 (2007).

3. Fulceri, F. et al. Motor skills as moderators of core symptoms in autism spectrum disorders: preliminary data from an exploratory analysis with artificial neural networks. Front. Psychol. https://doi.org/10.3389/fpsyg.2018.02683 (2019).

4. Paquet, A., Olliac, B., Bouvard, M.-P., Golse, B. \& Vaivre-Douret, L. The semiology of motor disorders in autism spectrum disorders as highlighted from a standardized neuro-psychomotor assessment. Front. Psychol. https://doi.org/10.3389/fpsyg. 2016.01292 (2016).

5. Paquet, A., Olliac, B., Golse, B. \& Vaivre-Douret, L. Current knowledge on motor disorders in children with autism spectrum disorder (ASD). Child Neuropsychol. 22, 763-794. https://doi.org/10.1080/09297049.2015.1085501 (2016).

6. Rinehart, N. \& McGinley, J. Is motor dysfunction core to autism spectrum disorder?. Dev. Med. Child Neurol. 52, 697-697. https://doi.org/10.1111/j.1469-8749.2010.03631.x (2010).

7. Bernard, J. A. \& Mittal, V. A. Cerebellar-motor dysfunction in schizophrenia and psychosis-risk: the importance of regional cerebellar analysis approaches. Front. Psychiatry 5, 160-160. https://doi.org/10.3389/fpsyt.2014.00160 (2014).

8. Walker, E., Lewis, N., Loewy, R. \& Palyo, S. Motor dysfunction and risk for schizophrenia. Dev. Psychopathol. 11, 509-523. https://doi.org/10.1017/s0954579499002187 (1999).

9. Hirjak, D. et al. Motor dysfunction within the schizophrenia-spectrum: a dimensional step towards an underappreciated domain. Schizophr. Res. 169, 217-233. https://doi.org/10.1016/j.schres.2015.10.022 (2015).

10. Walther, S. \& Strik, W. Motor symptoms and schizophrenia. Neuropsychobiology 66, 77-92. https://doi.org/10.1159/000339456 (2012).

11 Schäppi, L., Stegmayer, K., Viher, P. V. \& Walther, S. Distinct associations of motor domains in relatives of schizophrenia patients-different pathways to motor abnormalities in schizophrenia?. Front. Psychiatry https://doi.org/10.3389/fpsyt.2018. 00129 (2018).

12. Dahan, A. \& Reiner, M. Evidence for deficient motor planning in ADHD. Sci. Rep. 7, 9631. https://doi.org/10.1038/s41598-01709984-7 (2017).

13. Goulardins, J. B., Marques, J. C. \& De Oliveira, J. A. Attention deficit hyperactivity disorder and motor impairment. Percept. Mot. Skills 124, 425-440. https://doi.org/10.1177/0031512517690607 (2017).

14 Rosa Neto, F., Goulardins, J. B., Rigoli, D., Piek, J. P. \& Oliveira, J. A. D. Motor development of children with attention deficit hyperactivity disorder. Braz. J. Psychiatry 37, 228-234 (2015).

15. Caligiuri, M. P. \& Ellwanger, J. Motor and cognitive aspects of motor retardation in depression. J. Affect. Disord. 57, 83-93. https://doi.org/10.1016/s0165-0327(99)00068-3 (2000).

16. Mergl, R. et al. Hand-motor dysfunction in depression: characteristics and pharmacological effects. Clin. EEG Neurosci. 38, 82-88. https://doi.org/10.1177/155005940703800210 (2007).

17. Bennabi, D., Vandel, P., Papaxanthis, C., Pozzo, T. \& Haffen, E. Psychomotor retardation in depression: a systematic review of diagnostic, pathophysiologic, and therapeutic implications. Biomed. Res. Int. 2013, 158746. https://doi.org/10.1155/2013/158746 (2013).

18. Wolff, A. L. \& O'Driscoll, G. A. Motor deficits and schizophrenia: the evidence from neuroleptic-naive patients and populations at risk. J. Psychiatry Neurosci. 24, 304-314 (1999).

19. Peralta, V. \& Cuesta, M. J. Motor abnormalities: from neurodevelopmental to neurodegenerative through "functional" (neuro) psychiatric disorders. Schizophr. Bull. 43, 956-971. https://doi.org/10.1093/schbul/sbx089 (2017).

20. Torrey, E. F. Studies of individuals with schizophrenia never treated with antipsychotic medications: a review. Schizophr. Res. 58, 101-115. https://doi.org/10.1016/s0920-9964(02)00381-x (2002).

21. Blumer, D. Catatonia and the neuroleptics: psychobiologic significance of remote and recent findings. Compr. Psychiatry 38, 193-201. https://doi.org/10.1016/s0010-440x(97)90027-4 (1997).

22. Ungvari, G. S., Kau, L. S., Wai-Kwong, T. \& Shing, N. F. The pharmacological treatment of catatonia: an overview. Eur. Arch. Psychiatry Clin. Neurosci. 251(Suppl 1), I31-34. https://doi.org/10.1007/pl00014198 (2001).

23. Mosconi, M. W. \& Sweeney, J. A. Sensorimotor dysfunctions as primary features of autism spectrum disorders. Sci. China Life Sci. 58, 1016-1023. https://doi.org/10.1007/s11427-015-4894-4 (2015).

24. Takarae, Y., Minshew, N. J., Luna, B., Krisky, C. M. \& Sweeney, J. A. Pursuit eye movement deficits in autism. Brain 127, 2584-2594. https://doi.org/10.1093/brain/awh307 (2004).

25. Morrens, M., Hulstijn, W. \& Sabbe, B. Psychomotor slowing in schizophrenia. Schizophr. Bull. 33, 1038-1053. https://doi.org/ 10.1093/schbul/sbl051 (2007).

26. Vinogradov, S., Poole, J. H., Willis-Shore, J., Ober, B. A. \& Shenaut, G. K. Slower and more variable reaction times in schizophrenia: what do they signify?. Schizophr. Res. 32, 183-190. https://doi.org/10.1016/s0920-9964(98)00043-7 (1998). 
27. Henkel, V. et al. Kinematical analysis of motor function in schizophrenic patients: a possibility to separate negative symptoms from extrapyramidal dysfunction induced by neuroleptics?. Pharmacopsychiatry 37, 110-118. https://doi.org/10.1055/s-2004818988 (2004).

28. Mittal, V. A., Neumann, C., Saczawa, M. \& Walker, E. F. Longitudinal progression of movement abnormalities in relation to psychotic symptoms in adolescents at high risk of schizophrenia. Arch. Gen. Psychiatry 65, 165-171. https://doi.org/10.1001/ archgenpsychiatry.2007.23 (2008).

29. Honer, W. G., Kopala, L. C. \& Rabinowitz, J. Extrapyramidal symptoms and signs in first-episode, antipsychotic exposed and non-exposed patients with schizophrenia or related psychotic illness. J. Psychopharmacol. 19, 277-285. https://doi.org/10.1177/ 0269881105051539 (2005).

30. Athanasiadou, A. et al. Early motor signs of attention-deficit hyperactivity disorder: a systematic review. Eur. Child Adolesc. Psychiatry 29, 903-916. https://doi.org/10.1007/s00787-019-01298-5 (2020).

31. Kaiser, M. L., Schoemaker, M. M., Albaret, J. M. \& Geuze, R. H. What is the evidence of impaired motor skills and motor control among children with attention deficit hyperactivity disorder (ADHD)? Systematic review of the literature. Res. Dev. Disabil. 36C, 338-357. https://doi.org/10.1016/j.ridd.2014.09.023 (2015).

32. Paus, T., Keshavan, M. \& Giedd, J. N. Why do many psychiatric disorders emerge during adolescence?. Nat. Rev. Neurosci. 9, 947-957. https://doi.org/10.1038/nrn2513 (2008).

33. Kim-Cohen, J. et al. Prior juvenile diagnoses in adults with mental disorder: developmental follow-back of a prospectivelongitudinal cohort. Arch. Gen. Psychiatry 60, 709-717. https://doi.org/10.1001/archpsyc.60.7.709 (2003).

34. Bryson, S. E. et al. A prospective case series of high-risk infants who developed autism. J. Autism Dev. Disord. 37, 12-24. https:// doi.org/10.1007/s10803-006-0328-2 (2007).

35. Landa, R. J., Holman, K. C. \& Garrett-Mayer, E. Social and communication development in toddlers with early and later diagnosis of autism spectrum disorders. Arch. Gen. Psychiatry 64, 853-864. https://doi.org/10.1001/archpsyc.64.7.853 (2007).

36. Zwaigenbaum, L. et al. Behavioral manifestations of autism in the first year of life. Int. J. Dev. Neurosci. 23, 143-152. https://doi. org/10.1016/j.ijdevneu.2004.05.001 (2005).

37. Teitelbaum, P., Teitelbaum, O., Nye, J., Fryman, J. \& Maurer, R. G. Movement analysis in infancy may be useful for early diagnosis of autism. Proc. Natl. Acad. Sci. U. S. A. 95, 13982-13987. https://doi.org/10.1073/pnas.95.23.13982 (1998).

38. Visser, J. C., Rommelse, N. N., Greven, C. U. \& Buitelaar, J. K. Autism spectrum disorder and attention-deficit/hyperactivity disorder in early childhood: a review of unique and shared characteristics and developmental antecedents. Neurosci. Biobehav. Rev. 65, 229-263. https://doi.org/10.1016/j.neubiorev.2016.03.019 (2016).

39. Hans, S. L. et al. Neurobehavioral deficits at adolescence in children at risk for schizophrenia: the Jerusalem Infant Development Study. Arch. Gen. Psychiatry 56, 741-748. https://doi.org/10.1001/archpsyc.56.8.741 (1999).

40. Erlenmeyer-Kimling, L. et al. Attention, memory, and motor skills as childhood predictors of schizophrenia-related psychoses: the New York high-risk project. Am. J. Psychiatry 157, 1416-1422. https://doi.org/10.1176/appi.ajp.157.9.1416 (2000).

41. Liu, C. H., Keshavan, M. S., Tronick, E. \& Seidman, L. J. Perinatal risks and childhood premorbid indicators of later psychosis: next steps for early psychosocial interventions. Schizophr. Bull. 41, 801-816. https://doi.org/10.1093/schbul/sbv047 (2015).

42. Peleh, T., Eltokhi, A. \& Pitzer, C. Longitudinal analysis of ultrasonic vocalizations in mice from infancy to adolescence: insights into the vocal repertoire of three wild-type strains in two different social contexts. PLoS ONE 14, e0220238. https://doi.org/10. 1371/journal.pone.0220238 (2019).

43. Eltokhi, A., Kurpiers, B. \& Pitzer, C. Behavioral tests assessing neuropsychiatric phenotypes in adolescent mice reveal strain- and sex-specific effects. Sci. Rep. 10, 11263. https://doi.org/10.1038/s41598-020-67758-0 (2020).

44. Thibaut, F. The role of sex and gender in neuropsychiatric disorders. Dialogues Clin. Neurosci. 18, 351-352 (2016).

45. Voikar, V., Koks, S., Vasar, E. \& Rauvala, H. Strain and gender differences in the behavior of mouse lines commonly used in transgenic studies. Physiol. Behav. 72, 271-281. https://doi.org/10.1016/s0031-9384(00)00405-4 (2001).

46. Ashworth, A. et al. Comparison of neurological function in males and females from two substrains of C57BL/6 mice. Toxics 3 , 1-17. https://doi.org/10.3390/toxics3010001 (2015).

47. Chadman, K. K., Yang, M. \& Crawley, J. N. Criteria for validating mouse models of psychiatric diseases. Am. J. Med. Genet. B Neuropsychiatr. Genet. 150B, 1-11. https://doi.org/10.1002/ajmg.b.30777 (2009).

48. Crawley, J. N. et al. Behavioral phenotypes of inbred mouse strains: implications and recommendations for molecular studies. Psychopharmacology 132, 107-124. https://doi.org/10.1007/s002130050327 (1997).

49. Crawley, J. N. Behavioralphenotyping of rodents. Comp. Med. 53, 140-146 (2003).

50. Dutta, S. \& Sengupta, P. Men and mice: relating their ages. Life Sci. 152, 244-248. https://doi.org/10.1016/j.lfs.2015.10.025 (2016).

51. Taft, R. A., Davisson, M. \& Wiles, M. V. Know thy mouse. Trends Genet 22, 649-653. https://doi.org/10.1016/j.tig.2006.09.010 (2006).

52. Dunham, N. W. \& Miya, T. S. A note on a simple apparatus for detecting neurological deficit in rats and mice. J. Am. Pharm. Assoc. Am. Pharm. Assoc. 46, 208-209. https://doi.org/10.1002/jps.3030460322 (1957).

53. Kinnard, W. J. Jr. \& Carr, C. J. A preliminary procedure for the evaluation of central nervous system depressants. J. Pharmacol. Exp. Ther. 121, 354-361 (1957).

54. Tarantino, L. M., Gould, T. J., Druhan, J. P. \& Bucan, M. Behavior and mutagenesis screens: the importance of baseline analysis of inbred strains. Mamm Genome 11, 555-564. https://doi.org/10.1007/s003350010107 (2000).

55. McFadyen, M. P., Kusek, G., Bolivar, V. J. \& Flaherty, L. Differences among eight inbred strains of mice in motor ability and motor learning on a rotorod. Genes Brain Behav. 2, 214-219. https://doi.org/10.1034/j.1601-183x.2003.00028.x (2003).

56. Moy, S. S. et al. Social approach and repetitive behavior in eleven inbred mouse strains. Behav. Brain Res. 191, 118-129. https:// doi.org/10.1016/j.bbr.2008.03.015 (2008)

57. Moy, S. S. et al. Sociability and preference for social novelty in five inbred strains: an approach to assess autistic-like behavior in mice. Genes Brain Behav. 3, 287-302. https://doi.org/10.1111/j.1601-1848.2004.00076.x (2004).

58. Matsuo, N. et al. Behavioral profiles of three C57BL/6 substrains. Front. Behav. Neurosci. 4, 29. https://doi.org/10.3389/fnbeh. $2010.00029(2010)$

59. Wahlsten, D. et al. Different data from different labs: lessons from studies of gene-environment interaction. J. Neurobiol. 54, 283-311. https://doi.org/10.1002/neu.10173 (2003).

60. Hanell, A. \& Marklund, N. Structured evaluation of rodent behavioral tests used in drug discovery research. Front. Behav. Neurosci. 8, 252. https://doi.org/10.3389/fnbeh.2014.00252 (2014).

61. Rustay, N. R., Wahlsten, D. \& Crabbe, J. C. Assessment of genetic susceptibility to ethanol intoxication in mice. ProcNatlAcadSci U S A 100, 2917-2922. https://doi.org/10.1073/pnas.0437273100 (2003).

62. Rustay, N. R., Wahlsten, D. \& Crabbe, J. C. Influence of task parameters on rotarod performance and sensitivity to ethanol in mice. Behav. Brain Res. 141, 237-249. https://doi.org/10.1016/s0166-4328(02)00376-5 (2003).

63. Berkel, S. et al. Sex hormones regulate SHANK expression. Front. Mol. Neurosci. 11, 337. https://doi.org/10.3389/fnmol.2018. 00337 (2018).

64 Gillberg, C., Cederlund, M., Lamberg, K. \& Zeijlon, L. Brief report: "the autism epidemic". The registered prevalence of autism in a Swedish urban area. J. Autism Dev. Disord. 36, 429-435. https://doi.org/10.1007/s10803-006-0081-6 (2006).

65. Fombonne, E. Epidemiology of pervasive developmental disorders. Pediatr. Res. 65, 591-598. https://doi.org/10.1203/PDR. 0b013e31819e7203 (2009). 
66. Werling, D. M. The role of sex-differential biology in risk for autism spectrum disorder. Biol. Sex Differ. 7, 58. https://doi.org/ 10.1186/s13293-016-0112-8 (2016).

67. Nicole, L., Lesage, A. \& Lalonde, P. Lower incidence and increased male:female ratio in schizophrenia. Br. J. Psychiatry 161, 556-557. https://doi.org/10.1192/bjp.161.4.556 (1992).

68. McGrath, J. J. Variations in the incidence of schizophrenia: data versus dogma. Schizophr. Bull. 32, 195-197. https://doi.org/10. 1093/schbul/sbi052 (2006).

69. Rucklidge, J. J. Gender differences in attention-deficit/hyperactivity disorder. PsychiatrClin North Am 33, 357-373. https://doi. org/10.1016/j.psc.2010.01.006 (2010).

70. Martin, J. et al. A genetic investigation of sex bias in the prevalence of attention-deficit/hyperactivity disorder. Biol. Psychiatry 83, 1044-1053. https://doi.org/10.1016/j.biopsych.2017.11.026 (2018).

71. Mowlem, F. D. et al. Sex differences in predicting ADHD clinical diagnosis and pharmacological treatment. Eur. Child Adolesc. Psychiatry 28, 481-489. https://doi.org/10.1007/s00787-018-1211-3 (2019).

72. Ramtekkar, U. P., Reiersen, A. M., Todorov, A. A. \& Todd, R. D. Sex and age differences in attention-deficit/hyperactivity disorder symptoms and diagnoses: implications for DSM-V and ICD-11. J. Am. Acad. Child Adolesc. Psychiatry 49, 217-228.e283 (2010).

73. Cyranowski, J. M., Frank, E., Young, E. \& Shear, M. K. Adolescent onset of the gender difference in lifetime rates of major depression: a theoretical model. Arch. Gen. Psychiatry 57, 21-27. https://doi.org/10.1001/archpsyc.57.1.21 (2000).

74. Ford, D. E. \& Erlinger, T. P. Depression and C-reactive protein in US adults: data from the third national health and nutrition examination survey. Arch. Intern. Med. 164, 1010-1014. https://doi.org/10.1001/archinte.164.9.1010 (2004).

75. Patten, S. B. et al. Descriptive epidemiology of major depression in Canada. Can. J. Psychiatry 51, 84-90. https://doi.org/10. 1177/070674370605100204 (2006).

76. Salk, R. H., Hyde, J. S. \& Abramson, L. Y. Gender differences in depression in representative national samples: meta-analyses of diagnoses and symptoms. Psychol. Bull. 143, 783-822. https://doi.org/10.1037/bul0000102 (2017).

77. Bromet, E. et al. Cross-national epidemiology of DSM-IV major depressive episode. BMC Med. 9, 90. https://doi.org/10.1186/ 1741-7015-9-90 (2011).

78. Andrade, L. et al. The epidemiology of major depressive episodes: results from the International Consortium of Psychiatric Epidemiology (ICPE) surveys. Int. J. Methods Psychiatr. Res. 12, 3-21. https://doi.org/10.1002/mpr.138 (2003).

79 Young, L. \& Pfaff, D. Sex differences in neurological and psychiatric disorders. Front. Endocrinol. https://doi.org/10.1016/j.yfrne. 2014.05.005 (2014).

80 Wickens, M. M., Bangasser, D. A. \& Briand, L. A. Sex differences in psychiatric disease: a focus on the glutamate system. Front. Mol. Neurosci. https://doi.org/10.3389/fnmol.2018.00197 (2018).

81 Sacks, D., Canadian Paediatric, S. \& Adolescent Health, C. Age limits and adolescents. Paediatr. Child Health 8, 577-577. https:// doi.org/10.1093/pch/8.9.577 (2003).

82. Pintér, O., Beda, Z., Csaba, Z. \& Gerendai, I. Differences in the onset of puberty in selected inbred mouse strains. Endocr. Abstr. 14, P617 (2007).

83. Kovacs, A. D. \& Pearce, D. A. Location- and sex-specific differences in weight and motor coordination in two commonly used mouse strains. Sci. Rep. 3, 2116. https://doi.org/10.1038/srep02116 (2013).

84. Halloran, B. P. et al. Changes in bone structure and mass with advancing age in the male C57BL/6J mouse. J. Bone Miner. Res. 17, 1044-1050. https://doi.org/10.1359/jbmr.2002.17.6.1044 (2002).

85. Serradj, N. \& Jamon, M. Age-related changes in the motricity of the inbred mice strains 129/sv and C57BL/6j. Behav. Brain Res. 177, 80-89. https://doi.org/10.1016/j.bbr.2006.11.001 (2007).

86. Shoji, H. \& Miyakawa, T. Age-related behavioral changes from young to old age in male mice of a C57BL/6J strain maintained under a genetic stability program. Neuropsychopharmacol. Rep. 39, 100-118. https://doi.org/10.1002/npr2.12052 (2019).

87. Davis, M. J., Haley, T., Duvoisin, R. M. \& Raber, J. Measures of anxiety, sensorimotor function, and memory in male and female mGluR4(-)/(-) mice. Behav. Brain Res. 229, 21-28. https://doi.org/10.1016/j.bbr.2011.12.037 (2012).

88. Wahlsten, D., Bachmanov, A., Finn, D. A. \& Crabbe, J. C. Stability of inbred mouse strain differences in behavior and brain size between laboratories and across decades. Proc. Natl. Acad. Sci. U. S. A. 103, 16364-16369. https://doi.org/10.1073/pnas.06053 42103 (2006).

89. Editorial Nature Neuroscience. Troublesome variability in mouse studies. Nat. Neurosci. 12, 1075. https://doi.org/10.1038/ nn0909-1075 (2009).

90. Mandillo, S. et al. Early motor deficits in mouse disease models are reliably uncovered using an automated home-cage wheelrunning system: a cross-laboratory validation. Dis. Model Mech. 7, 397-407. https://doi.org/10.1242/dmm.013946 (2014).

91 Hamers, F., Koopmans, G. \& Joosten, E. CatWalk-assisted gait analysis in the assessment of spinal cord injury. J. Neurotrauma https://doi.org/10.1089/neu.2006.23.537 (2006).

92. Van Der Giessen, R. S. et al. Role of olivary electrical coupling in cerebellar motor learning. Neuron 58, 599-612. https://doi. org/10.1016/j.neuron.2008.03.016 (2008).

93. Chesler, E. J., Wilson, S. G., Lariviere, W. R., Rodriguez-Zas, S. L. \& Mogil, J. S. Influences of laboratory environment on behavior. Nat. Neurosci. 5, 1101-1102. https://doi.org/10.1038/nn1102-1101 (2002).

94. Lopez-Aumatell, R. et al. Effects of environmental and physiological covariates on sex differences in unconditioned and conditioned anxiety and fear in a large sample of genetically heterogeneous (N/Nih-HS) rats. Behav. Brain Funct. 7, 48. https://doi. org/10.1186/1744-9081-7-48 (2011).

95. Oliva, A. M. et al. Toward a mouse neuroethology in the laboratory environment. PLoS ONE 5, e11359. https://doi.org/10.1371/ journal.pone.0011359 (2010).

96. Kulesskaya, N., Rauvala, H. \& Voikar, V. Evaluation of social and physical enrichment in modulation of behavioural phenotype in C57BL/6J female mice. PLoS ONE 6, e24755. https://doi.org/10.1371/journal.pone.0024755 (2011).

97. Munn, E. et al. Reversed light-dark cycle and cage enrichment effects on ethanol-induced deficits in motor coordination assessed in inbred mouse strains with a compact battery of refined tests. Behav. Brain Res. 224, 259-271. https://doi.org/10.1016/j.bbr. 2011.05.030 (2011).

98. Izidio, G. S., Lopes, D. M., Spricigo, L. Jr. \& Ramos, A. Common variations in the pretest environment influence genotypic comparisons in models of anxiety. Genes Brain Behav. 4, 412-419. https://doi.org/10.1111/j.1601-183X.2005.00121.x (2005).

99. Yoshida, S., Numachi, Y., Matsuoka, H. \& Sato, M. Impairment of cliff avoidance reaction induced by subchronic methamphetamine administration and restraint stress: comparison between two inbred strains of rats. Prog. Neuropsychopharmacol. Biol. Psychiatry 22, 1023-1032. https://doi.org/10.1016/s0278-5846(98)00050-5 (1998).

100 Pitzer, C., Kuner, R. \& Tappe-Theodor, A. EXPRESS: Voluntary and evoked behavioral correlates in neuropathic pain states under different housing conditions. Mol. Pain https://doi.org/10.1177/17448806916656635 (2016).

\section{Acknowledgements}

We would like to thank Shaimaa Madbouly and Dr. Rolf Sprengel for their constant support and Denise Korn for animal breeding and care. We thank Prof. Margot Zöller for proofreading the manuscript. 


\section{Author contributions}

A.E. and C.P. conceptualize and designed the study. A.E. and B.K. performed behavioral experiments and analysis. A.E. and C.P. performed data interpretation. A.E. prepared the figures. A.E. and C.P. wrote the manuscript. All authors reviewed the manuscript.

\section{Funding}

Open Access funding enabled and organized by Projekt DEAL.

\section{Competing interests}

The authors declare no competing interests.

\section{Additional information}

Supplementary Information The online version contains supplementary material available at https://doi.org/ 10.1038/s41598-021-85858-3.

Correspondence and requests for materials should be addressed to A.E. or C.P.

Reprints and permissions information is available at www.nature.com/reprints.

Publisher's note Springer Nature remains neutral with regard to jurisdictional claims in published maps and institutional affiliations.

(c) (i) Open Access This article is licensed under a Creative Commons Attribution 4.0 International License, which permits use, sharing, adaptation, distribution and reproduction in any medium or format, as long as you give appropriate credit to the original author(s) and the source, provide a link to the Creative Commons licence, and indicate if changes were made. The images or other third party material in this article are included in the article's Creative Commons licence, unless indicated otherwise in a credit line to the material. If material is not included in the article's Creative Commons licence and your intended use is not permitted by statutory regulation or exceeds the permitted use, you will need to obtain permission directly from the copyright holder. To view a copy of this licence, visit http://creativecommons.org/licenses/by/4.0/.

(C) The Author(s) 2021 